clear recently.

Therapeutic modalities of malignant lymphomas are decided according to their histology, clinical stages, tumor cell origin and all other findings. Radiotherapy is most effective, but ineffective for the tumor cells outside the field. Chemotherapy is effective widely in the whole body but relapse occurs sometimes in the lesion where bulky mass initially existed.

Actually, one of the followings is selected.
(1) Mild chemotherapy with a drug is used like in chronic leukemias for the disease with a good risk, even at its advanced stage. (2) radiotherapy for the localized disease, (3) operative treatment in some cases like gastrointestinal lymphomas, (4) intensive multi-drug combination chemotherapy for the advanced disease, (5) combined radio-chemotherapy for an advanced diseases with bulky masses, (6) super strong radio-chemotherapy followed by bone marrow transplantation.

\title{
1. The Changing Concept and Classification of Malignant Lymphomas
}

\author{
Taizan Suchi, MD \\ Department of Pathology and Clinical Laboratories, Aichi Cancer Center Hospital, Nagoya
}

Remarkable progress in immunology in the latter half of the 20th century has clarified the structures and functions of immune tissue and its component cells, which subsequently changed dramatically our concepts of malignant lymphomas. The new era of malignant lymphomas which can be called the immunological age has inevitably brought about changes in the principles of lymphoma classification. This article deals with the history of lymphoma classification with special references to its recent development.

\section{From T. Hodgkin to D. Burkitt}

The history of lymphoma classification has been known to be that of confusion and chaos from the beginning. The paucity of knowledges on the lymphoreticular or immune tissue was largely responsible for this chaos in the concept and nomenclature, but the existence of lesions of border-line atypicality and the dispute over relation between leukemia and lymphoma also helped in the making of the confusion.

When Thomas Hodgkin ${ }^{1)}$ first described malignant tumors of lymph node and spleen in 1832, he actually included lesions of other lymphomatous conditions besides Hodgkin's disease of the present-day. Virchow (1863) 2 ) proposed the term "lymphosarcoma" by which he meant an entity clearly different from "leukemia" he previously defined. And Hodgkin's disease seemed to be included in that category. In the following few decades, the term lymphosarcoma as well as strange names such as lymphadenosis and pseudoleukemia were used to include a fairly broad spectrum of lymphoid neoplasms.

After this period, Hodgkin's disease at first,

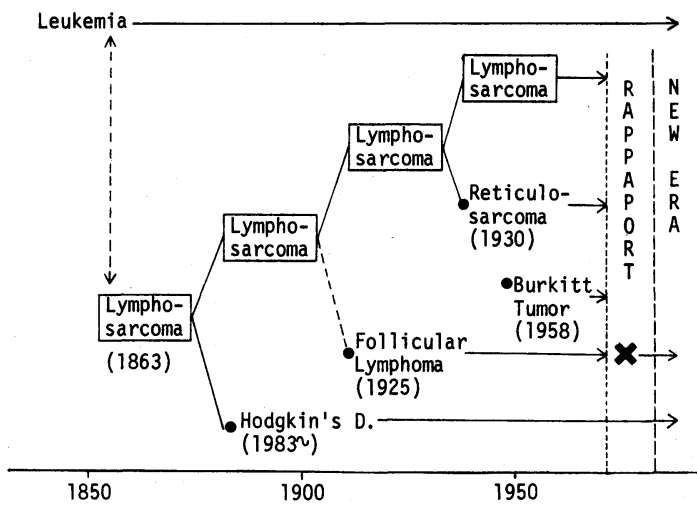

Fig. 1. Schematic Illustration of the History of Lymphoma Classification. 
then follicular lymphoma ${ }^{3,4)}$ and reticulum cell sarcoma 5 , 6) have been separated from "lymphosarcoma", as definite pathological entities. Whenever the separation of an entity took place, it subsequently altered somewhat the content of remaining "lymphosarcoma". The only entity which is unique in the history of lymphomas is the Burkitt's tumor, ${ }^{7}$ ) which emerged from the outside world as an entirely new disease and was later established as a form of lymphomas. The history of changing concept is schematically illustrated in Fig. 1.

\section{New Characterizations of Lymphomas}

Before the coming of new era, two classifications were commonly used in Japan, namely the conventional or Akazaki's classification ${ }^{8)}$ which consisted of 4 major categories, i.e., lymphosarcoma, reticulum cell sarcoma, follicular lymphoma and Hodgkin's disease, and the Rappaport classification $^{\text {9) }}$ for non-Hodgkin's lymphomas. The latter was being increasingly used in Japan as well as in many other countries of the world, owing partly to the evangelistic power of the AFIP atlas "the Bible", but also to the reputation that it had more clinical usefulness than any other classifications as prognostic indicators. The classification, however, had its fault in degrading the nodular or follicular pattern of follicular lymphomas to a mere histological pattern without basic meaning. The germinal center nature of the follicular pattern was later restored by Kojima ${ }^{10)}$ and Lennert ${ }^{11)}$ largely on the bases of electromicroscopic findings, and subsequently firmly proved by immunological methods. ${ }^{12)}$

The most significant development at the advent of the new era was probably the collapse of reticulum cell sarcoma. The term reticulum cell sarcoma was based on the concept that those large-celled lymphomas were tumors of reticulum cells, the principal cells of the reticulo-endothelial system (RES). Since the reticulum cell is a precursor of histiocytes in the RES theory, the histiocytic lymphoma in the Rappaport classification is of the same line of thinking. This concept of reticulum cell-histiocytic origin of these lymphomas was suddenly collapsed when the B- or T-lymphocyte markers were easily revealed on the cells of these tumors by relatively simple methods of investigations. ${ }^{13)}$

At about the same time, the immunological characters of two distinct "childhood" lymphomas namely lymphoblastic lymphomas and Burkitt lymphomas were also clarified. The former was revealed to be of thymic cortical lymphocyte nature $\left(T_{1}\right)$, and the latter, to be of immature $B$ lymphocyte $\left(\mathrm{B}_{1}\right)$.

\section{New Classifications}

Thus the immunological concept of malignant lymphomas has been gradually established by accumulation of new knowledges through increasing refinement of investigation methods. It inevitably affected the principles of classification, and many new classifications for non-Hodgkin's lymphomas have been advocated by many single and groups of authors. ${ }^{14)}$ Among them, LukesCollins, $^{15)}$ and Kiel classifications ${ }^{16)}$ are most radical in the immunological point of view.

In Japan, meanwhile, the adult T-cell leukemia, a peculiar form of endemic lymphoma-leukemia with peripheral T-cell nature was found by Takatsuki et al. ${ }^{17)}$ as early as in 1974 . The tumors in this disease are histologically composed of various sized lymphoid cells in varing proportions, showing marked nuclear polymorphism with many hyperconvoluted and multilobulated nuclei,

Table 1. LSG Classification for non-Hodgkin's lymphomas.

\section{LSG Classification}

Follicular Lymphoma
Medium-sized Cel1 Type (B)
Mixed Type (B)
Large Cell Type (B)
Diffuse Lymphoma
Small Cell Type (B,T)
Medium-sized Ce 11 Type $(B, T)$
Mixed Type (B, T)
Large Cell Type (B,T,Nul1)
inc. Immunoblastic Type (B)
* PLEOMORPHIC TYPE ( $T_{2}$ )
Lymphoblastic Type (T, Nu11)
Burkitt Type (B)


as well as occasional multinucleated giant cells of similar nature and/or resembling Reed-Sternberg cell. Based on these facts, we, member pathologists of the Lymphoma Study Group (LSG) of Japan advocated an independent subtype, pleomorphic lymphoma ${ }^{18)}$ for this kind of histology in a scheme of classification as a new system suited for non-Hodgkin's lymphomas in Japan.

This classification, as shown in Table 1, divides diffuse lymphomas other than the previously described distinct entities into 4 subtypes according to their nuclear sizes. It advises to add after the subtypes qualifying remarks such as $\mathrm{T}$ - and B-cell characters or plasmacytoid and other features whenever possible.

With the exceptions of pleomorphic type and other minor differences, the classification corresponds well with the scheme of the Working Formulation of Non-Hodgkin's Lymphomas for Clinical Usage $(W F)^{14)}$ formulated under the NCI project in 1980. The LSG Classification is being increasingly adopted by pathologists and hematologists within Japan in these days.

\section{REFERENCES}

1) Hodgkin $T$ : On some morbid appearance of the absorbent glands and spleen. Med-Chir Trans 17: $68,1832$.

2) Virchow R: Die Krankhaften Geschwülste. Dreissing Vorlesungen gehalten während des Wintersemesters 1862-1863 an der Universität Berlin. Vol. 2, Berlin, $1864 / 65$.

3) Brill NE, Baehr $\mathrm{G}$ and Rosenthal N: Generalized giant lymph follicle hyperplasia of lymph nodes and spleen; a hitherto undescribed type. JAMA 84: 668, 1925.

4) Symers D: Giant follicular lymphadenopathy with or without splenomegaly. AMA Arch Path 26: 603, 1938.

5) Roulet F: Das primäre Retothelsarkom der Lymphknoten. Virchows Arch 277: 15, 1930.

6) Rössle R: Das Retothelsarkom der Lymphdrüsen.
Sein Formen und Verwandtschaften. Beitr Path Anat 103: 385, 1939.

7) Burkitt DP: A sarcoma involving the jaws in African Children. Brit J Surg 46: 218, 1958/59.

8) Akazaki K: Tumors of the Reticulo-Endothelial System. Acta Pathologica Japonica 3: 24, 1953.

9) Rappaport H: Tumors of the Hematopoietic System. Atlas of Tumor Pathology, Sect 3, Fasc 8, AFIP, 1966.

10) Kojima M, Imai $Y$ and Mori N: A Concept of Follicular Lymphoma-A Proposal for the Existence of a Neoplasm Originating from the Germinal Center. Malignant diseases of the hematopoietic System Gann Monograph on Cancer Research 15, Univ. of Tokyo Press Tokyo, p 195.

11) Lennert K: Follicular Lymphoma-A Tumor of the Germinal Centers. Akazaki K, Rappaport H, Berard CW, et al (Eds) Malignant Diseases of the hematopoietic System Gann Monograph on Cancer Research 15, Univ of Tokyo Press, Tokyo, 1973.

12) Jaffe ES, Shevach EM, Frank MM, et al: Nodular lymphoma: evidence for origin from follicular B lymphocytes. New Engl J Med 290: 813, 1974.

13) Brouet JC, Preud'Homme JL, Flandrin G, et al: Brief Communication: Membrane Markers in "Histiocytic" Lymphomas (Reticulum Cell Sarcomas). National Cancer Institute 56: 631, 1976.

14) The Non-Hodgkin's Lymphoma Pathologic Classification Project: National Cancer Institute Sponsored Study of Classifications of Non-Hodgkin's Lymphomas. Summary and Description of a Working Formulation for Clinical Usage. Cancer 49: 2112, 1982.

15) Lukes RJ and Collins RD: Lukes-Collins Classification and its Significance. Cancer Treat Rep 61: 971, 1977.

16) Lennert K: Malignant Lymphomas other than Hodgkin's Disease, edit, Lennert K, Springer-Verlag, 1978.

17) Takatsuki $K$, Uchiyama $T$, Ueshima $Y$, et al: Adult $T$ cell leukemia: Proposal as a new disease and cytogenetic, phenotypic, and functional studies of leukemic cells. Gann Monograph Cancer Res 28: $13,1982$.

18) Suchi $T$, Tajima $K$, Nanba $K$, et al: Some problems on the histopathological diagnosis of non-Hodgkin's malignant lymphoma. - A proposal of a new type -. Acta Path Jap 29: 755, 1979. 